4(1) $1-10$

Jp.jok (Jurnal Pendidikan Jasmani, Olahraga dan Kesehatan)

http://ejurnal.budiutomomalang.ac.id/index.php/jpjok

Doi : https://doi.org/10.33503/jp.jok.v4i1.829

\title{
Motivation And Student Learning Outcomes In Problem Based Learning
}

\author{
Firdaus Febri Arisetiyana ${ }^{1)}$, Dwi Cahyo Kartiko ${ }^{2)}$, Nanik Indahwati ${ }^{3)}$, Bayu \\ Budi Prakoso $^{4)}$ \\ Program studi S2 Pendidikan Olahraga, Pascasarjana \\ 1,2,3,4 Universitas Negeri Surabaya, Jawa Timur Indonesia \\ Email: ${ }^{1}$ firdausarisetiyana16070805006@mhs.unesa.ac.id \\ ² $\underline{\text { dwicahyo@unesa.ac.id, }},{ }^{3}$ nanikindahwati@unesa.ac.id,, bayuprakoso@unesa.ac.id
}

\begin{abstract}
Applying eclectic learning means combining two or more learning models to be applied at one time. This article aims to analyze students' motivation and learning outcomes in participating in a combination of learning from problem based learning $(P B L)$ with cooperative learning. This research is weak-experimental using static-group pretest-posttest design. A total of 52 students (male $=35$, female $=17)$ 8th grade junior high school were taken using the cluster random sampling method. Motivation data are collected using a questionnaire, while learning outcomes use skills tests. PBL as the main model combined with cooperative type team game tournament (TGT) and jigsaw is applied as a treatment. Data analysis using descriptive statistics and t-test. The results showed that motivation $[t(25)=51.97, p=0.000]$ and learning outcomes $[t(25)=$ 13.41, $p=0.000]$ increased significantly in the PBL-TGT group. Likewise with motivation [t $(25)=$ $48.88, p=0.000]$ and learning outcomes $[t(25)=11.74, p=0.000]$ in the PBL-Jigsaw group. There was no difference in increased motivation $(t(50)=0.963, p=0.34)$ and learning outcomes $(t(50)=$ $0.000, p=1.000$ ) in the two groups. It can be concluded that PBL is compatible combined with TGT and Jigsaw in increasing motivation and learning outcomes.
\end{abstract}

Keywords: Eclectic, Motivation, Learning Outcomes, Cooperative Learning, Problem Based Learning.

\section{Motivasi Dan Hasil Belajar Siswa Dalam Pembelajaran Berbasis Masalah ABSTRAK}

Menerapkan pembelajaran eklektik berarti mengombinasikan dua atau lebih model pembelajaran untuk diterapkan dalam satu waktu. Artikel ini bertujuan untuk menganalisis motivasi dan hasil belajar siswa dalam mengikuti pembelajaran kombinasi dari pembelajaran berbasis masalah dengan cooperative learning. Penelitian ini merupakan weak-experimental dengan menggunakan static-group pretest-posttest design. Sebanyak 52 siswa (putra= 35, putri= 17) SMP kelas 8 diambil menggunakan metode cluster random sampling. Data motivasi dikumpulkan menggunakan angket, sedangkan hasil belajar menggunakan tes keterampilan. PBL sebagai model utama dikombinasikan dengan kooperatif tipe team game tournament (TGT) dan jigsaw diterapkan sebagai treatment. Analisis data menggunakan deskriptif statistik dan $t$-test. Hasil menunjukkan bahwa motivasi $[\mathrm{t}(25)=51,97, \mathrm{p}=0,000]$ dan hasil belajar $[\mathrm{t}(25)=13,41, \mathrm{p}=0,000]$ meningkat secara signifikan pada kelompok PBL-TGT. Begitu pula dengan motivasi $[\mathrm{t}(25)=$ $48,88, \mathrm{p}=0,000]$ dan hasil belajar $[\mathrm{t}(25)=11,74, \mathrm{p}=0,000]$ dalam kelompok PBL-Jigsaw. Tidak ada perbedaan peningkatan motivasi $[\mathrm{t}(50)=0,963, \mathrm{p}=0,34]$ dan hasil belajar $[\mathrm{t}(50)=0, \mathrm{p}=1,000]$ pada kedua kelompok. Dapat disimpulkan bahwa PBL sama-sama cocok dikombinasikan dengan TGT maupun Jigsaw dalam meningkatkan motivasi dan hasil belajar.

Kata Kunci: Eklektik, Motivasi, Hasil Belajar, Cooperative Learning, Problem Based Learning. (C) 2020 IKIP BUDI UTOMO MALANG

Info Artikel

Dikirim

Diterima
P-ISSN 2613-9421

E-ISSN 2654-8003

Alamat korespondensi: bayuprakoso@unesa.ac.id

Universitas Negeri Surabaya, Jl. Ketintang No.30, Ketintang, Kec. Gayungan, Kota SBY, Jawa Timur 60231, Indonesia 


\section{PENDAHULUAN}

Banyak pilihan model pembelajaran untuk dapat diterapkan dalam mata pelajaran Pendidikan Jasmani, Olahraga, dan Kesehatan (PJOK). Menurut (Metzler, 2011) ada 10 model pembelajaran yang biasa digunakan dalam pembelajaran PJOK yaitu direct instruction, personalized system for instruction, cooperative learning, sport education, peer teaching, inquiry teaching, tactical games, teaching personal and social, and responsibility. Akan tetapi, pemerintah Indonesia memberikan rekomendasi enam model pembelajaran yang cocok untuk menerapkan kurikulum 2013 yaitu model saintifik, cooperative learning, inquiry/discovery, problem learning, project based learning, dan model eklektik (Suroto, 2017).

Dari banyak pilihan model pembelajaran tersebut, guru perlu memilih model yang tepat agar layanan belajar kepada siswa dapat optimal. Pemilihan model pembelajaran yang tepat untuk memberikan layanan belajar pada siswa harus didasari oleh pemahaman pedagogik mengenai model pembelajaran karena hal ini menjadi kunci dari kualitas proses pembelajaran selanjutnya (Todd, Begoña, \& Carol, 2016). Berbekal dengan pemahaman tentang berbagai model pembelajaran, guru dapat meramu beberapa model pembelajaran diterapkan dalam satu waktu. Meramu beberapa model pembelajaran menjadi satu disebut dengan model eklektik dengan sintak (1) merumuskan indikator/tujuan pembelajaran yang sesuai dengan kompetensi dasar; (2) mengeksplorasi metode pembelajaran beserta fitur-fiturnya dan memilih fitur-fitur yang akan digabungkan dan digunakan guru dalam pembelajaran yang sesuai dengan tujuan pembelajaran/sarana prasarana/waktu pembelajaran; dan (3) menuliskan urutan fitur-fitur yang akan dipadukan sebagai kegiatan inti pembelajaran (Ministry of National Education of Republic of Indonesia, 2016).

Artikel ini berisi tentang penjelasan dari hasil penerapan kombinasi dua model pembelajaran yaitu pembelajaran berbasis masalah dan cooperative learning. Mengombinasikan dua model ini dirasa menarik karena karakteristik dari dua model ini yang unik. Para peneliti berpendapat bahwa desain pembelajaran yang menerapkan problem based learning diyakini dapat berdampak pada kognitif atau psikologis siswa, mengajarkan kemandirian belajar, 
bahkan menjamin keterlibatan siswa dalam pembelajaran (Hung, Mehl, \& Holen, 2013). Selain itu, sebagian besar penelitian tentang cooperative learning bertujuan untuk menciptakan proses pembelajaran sosial dengan fokus pada motivasi, iklim kelompok, dan interaksi guru-siswa (Bores-García, Hortigüela-Alcalá, FernandezRio, González-Calvo, \& Barba-Martín, 2020). Kombinasi dua model ini diharapkan dapat mendukung perkembangan kompetensi siswa sesuai dengan tuntutan abad 21, yaitu critical thingking, collaboration, communication, and creativity (Suroto, 2018). Sebagai tujuan akhir dari pembelajaran yang terpenting adalah meningkatkan efektivitas pembelajaran yang biasa diukur dengan keterlibatan siswa yang biasa berhubungan dengan motivasi dan hasil belajar (Nuriawati, Suroto, Tuasikal, \& Setyorini, 2020).

Mengombinasikan beberapa model pembelajaran membutuhkan proses yang tidak sembarang, harus melalui proses sistematis yang dapat dipertanggungjawabkan. Proses penelitian merupakan salah satu cara yang dapat menghasilkan bukti credible untuk dijadikan rujukan oleh guru dalam memberikan layanan belajar kepada siswa lebih optimal dan variatif. Kombinasi model problem based learning dalam artikel ini menjadi model utama yang diiringi oleh model cooperative TGT dan Jigsaw. Cooperative learning pada umumnya adalah pembelajaran kelompok yang memiliki tujuan untuk membelajarkan siswa dalam mencapai tujuan bejalar akademik, menerima perbedaan, dan melatih keterampilan sosial, tipe TGT berfokus kepada aktivitas kompetitif antar kelompok sedangkan Jigsaw berfokus pada saling membantu dalam belajar antara siswa ahli dan siswa asal (Suroto, 2017).

Sesuai dengan pedoman pembelajaran SMP, sintak model problem based learning sebagai model utama akan lebih banyak digunakan dibandingkan dengan model cooperative sebagai model yang mengiringi (Ministry of National Education of Republic of Indonesia, 2016). Untuk itu, nuansa pembelajaran masih sangat dominan pada model pembelajaran utama yaitu model problem based learning. Hal ini merupakan hal baru yang dilakukan peneliti sebagai seorang guru sehingga perlu diperiksa dampaknya terhadap variabel penting dalam pembelajaran yaitu motivasi (Burstiando, 2015) dan hasil belajar sebagai tujuan utama proses pembelajaran (Prakoso, 2015). Untuk itu, sebagai tindakan baru 
yang dilakukan oleh guru dalam mengombinasikan beberapa model pembelajaran yang berbeda maka tujuan artikel ini adalah menguji proses pembelajaran PJOK berbasis masalah berdasarkan motivasi dan hasil belajar siswa.

Motivasi belajar dartikan sebagai daya penggerak siswa dalam meraih tujuan belajar (Gunawan, 2019). Hasil belajar diartikan sebagai capaian belajar siswa berupa sikap, pengetahuan, dan keterampilan yang berkembang setelah siswa mengikuti proses pembelajaran (Suroto, 2017). Motivasi menjadi variabel penting dalam proses pembelajaran karena diyakini memberikan kontribusi positif terhadap hasil belajar siswa (Awe \& Benge, 2017). Sehingga tidak berlebihan apabila variabel motivasi dan hasil belajar ini perlu dikaji dalam penerapan model pembelajaran, terutama hal baru yang sedang diterapkan oleh guru dalam proses pembelajaran PJOK.

\section{METODE}

\section{Rancangan penelitian}

Jenis penelitian ini adalah weak experimental menggunakan static-group pretest-posttest design untuk melaksanakan penelitian, yaitu penelitian yang tidak selalu melibatkan kelompok kontrol (Fraenkel, Wallen, \& Hyun, 2012). Ilustrasi desain dapat dilihat pada tabel 1 sebagai berikut.

Tabel 1. Ilustrasi Desain Penelitian

\begin{tabular}{|c|c|c|c|c|}
\hline TGT & $\mathrm{R}$ & $\begin{array}{c}\mathrm{O} \\
\text { Pretest } \\
\text { Motivasi dan hasil } \\
\text { belajar } \\
\end{array}$ & $\begin{array}{c}\mathrm{X}_{1} \\
\text { Treatment } \\
\text { TGT berbasis } \\
\text { Masalah } \\
\end{array}$ & $\begin{array}{c}\mathrm{O} \\
\text { Posttest } \\
\text { Motivasi dan hasil } \\
\text { belajar } \\
\end{array}$ \\
\hline Jigsaw & $\mathrm{R}$ & $\begin{array}{c}\mathrm{O} \\
\text { Pretest } \\
\text { Motivasi dan hasil } \\
\text { belajar }\end{array}$ & $\begin{array}{c}\mathrm{X} 2 \\
\text { Treatment } \\
\text { Jigsaw berbasis } \\
\text { Masalah }\end{array}$ & $\begin{array}{c}\mathrm{O} \\
\text { Posttest } \\
\text { Motivasi dan hasil } \\
\text { belajar }\end{array}$ \\
\hline
\end{tabular}

\section{Sumber data}

Penelitian ini dilakukan di SMPN 2 Sumenep, Jawa Timur. Populasi penelitian adalah seluruh siswa kelas VIII sebanyak 289 siswa terdiri atas 167 laki-laki dan 122 perempuan. Jumlah kelas VIII adalah 10 kelas, yaitu kelas VIII1 sampai dengan VIII-10. Metode cluster random sampling digunakan untuk memilih sampel. Mekanisme random selection digunakan untuk memilih dua kelas sebagai kelompok yang akan menerima pembelajaran PBL-TGT atau PBLJigsaw, dua kelas yang terpilih adalah kelas VIII-7 dan VIII-8 sedangan 
mekanisme random assignment digunakan untuk menentukan kelas yang mendapatkan model PBL-TGT adalah VIII-8 sedangkan PBL-Jigsaw adalah VIII7. Jumlah siswa di kelas VIII-7 sebanyak 26 siswa terdiri atas laki-laki 18 dan perempuan 8 sedangkan jumlah siswa di kelas VIII-8 sebanyak 26 siswa terdiri atas laki-laki 17 dan perempuan 9.

\section{Teknik pengumpulan data}

Data penelitian dikumpulkan menggunakan angket motivasi dan tes keterampilan hasil belajar bolavoli. Motivasi diukur dengan mengungkap motivasi belajar siswa pada aspek intrinsik dan ekstrinsik (Burstiando, 2015). Angket motivasi divalidasi oleh ahli psikologi olahraga dengan hasil validasi sebesar $75 \%$ (baik). Sedangkan tes keterampilan hasil belajar bolavoli terdiri atas tes passing bawah, atas, dan service. Metode penilaian menggunakan process-oriented dengan validitas isi menurut ahli sebesar $87 \%$ (baik sekali).

\section{Analisis data}

Analisis data menggunakan deskriptif statistik. Normalitas distribusi data ditentukan menggunakan skewness dengan aturan $-1 \leq$ skewness $\leq 1$ (Meyers, Gamst, \& Guarino, 2013). Perbedaan nilai pretest dan posttest dianalisis menggunakan t-test dependent. Sedangkan perbedaan $\Delta$ mean antar group dianalisis menggunakan $t$-test independent.

\section{HASIL DAN PEMBAHASAN}

Hasil penelitian pada tabel 1 berikut ini adalah hasil analisis data menggunakan deskriptif statistik.

Tabel 2. Deskriptif Statistik Motivasi dan Hasil Belajar Siswa

\begin{tabular}{llllrrrrr}
\hline \multicolumn{1}{c}{ Group } & Variabel & Test & N & Mean & SD & Min. & Max. & Skewness \\
\hline PBL-TGT & Motivasi belajar & Pre & 26 & 69,7 & 2,95 & 65 & 78 & 0,509 \\
& & Post & 26 & 99,2 & 2,09 & 96 & 104 & 0,689 \\
& \multirow{4}{*}{ Hasil belajar } & Pre & 26 & 57,7 & 17,47 & 25 & 92 & $-0,063$ \\
& & Post & 26 & 73,5 & 18,33 & 42 & 100 & $-0,167$ \\
PBL- & \multirow{4}{*}{ Motivasi belajar } & Pre & 26 & 68,5 & 2,98 & 60 & 73 & $-0,962$ \\
& & Post & 26 & 98,8 & 1,99 & 96 & 104 & 0,545 \\
& \multirow{4}{*}{ Hasil belajar } & Pre & 26 & 56,5 & 16,20 & 25 & 83 & $-0,329$ \\
& & Post & 26 & 72,2 & 16,76 & 42 & 100 & $-0,362$ \\
\hline
\end{tabular}


Motivasi belajar siswa pada kelompok PBL-TGT meningkat dari nilai 69,7 saat pretest menjadi 99,2 saat posttest. Pada kelompok PBL-Jigsaw, motivasi belajar siswa meningkat dari nilai pretest sebesar 68,5 menjadi 98,8 saat posttest. Hasil belajar siswa pada kelompok PBL-TGT meningkat dari nilai 57,7 saat pretest berubah menjadi 73,5 saat posttest. Pada kelompok PBL-Jigsaw, hasil belajar siswa meningkat dari nilai pretest sebesar 56,5 menjadi 72,2 saat posttest. Pada setiap distribusi data dapat dilihat bahwa nilai skewness berkisar antara 0,962-0,689. Artinya bentuk distribusi data dinyatakan simetrik, atau distribusi data yang terbentuk dinyatakan normal (Meyers et al., 2013). Sehingga nilai mean dapat merepresentasikan nilai dalam distribusi. Hasil penelitian berikutnya dianalsis dengan menggunakan t-test dependent untuk mengetahui perbedaan mean pretest dan posttest motivasi dan hasil belajar siswa di setiap kelompok. Hasil analisis ada dalam tabel 2.

Tabel 3. Perbedaan Mean Pretest-Posttest Motivasi dan Hasil Belajar Siswa

\begin{tabular}{lccccccccc}
\hline Group & Variabel & Test & Mean & $\Delta$ & $\boldsymbol{\%} \Delta$ & $\boldsymbol{t}$ & $\boldsymbol{d f}$ & Sig. & Simpulan \\
\hline PBL- & Motivasi belajar & Post & 99,2 & 29,4 & $42 \%$ & 51,97 & 25 & 0,000 & Signifikan \\
TGT & & Pre & 69,7 & & & & & & \\
& Hasil belajar & Post & 73,5 & 15,7 & $27 \%$ & 13,41 & 25 & 0,000 & Signifikan \\
& & Pre & 57,7 & & & & & & \\
PBL- & Motivasi belajar & Post & 98,8 & 30,2 & $44 \%$ & 48,88 & 25 & 0,000 & Signifikan \\
Jigsaw & & Pre & 68,5 & & & & & & \\
& Hasil belajar & Post & 72,2 & 15,7 & $28 \%$ & 11,74 & 25 & 0,000 & Signifikan \\
& & Pre & 56,5 & & & & & & \\
\hline
\end{tabular}

Isi tabel 2 di atas dapat dijelaskan bahwa pada kelompok PBL-TGT, motivasi belajar meningkat secara signifikan dari pretest ke posttest dibuktikan dengan nilai $\mathrm{t}(25)=51,97, p=0,000$, besar peningkatan sebesar $42 \%$. Pada kelompok PBL-Jigsaw, motivasi belajar meningkat secara signifikan dari pretest ke posttest dibuktikan dengan nilai $\mathrm{t}(25)=48,88, p=0,000$, besar peningkatan sebesar $44 \%$.

Sedangkan untuk variabel hasil belajar, pada kelompok PBL-TGT, nilai hasil belajar meningkat secara signifikan dari pretest ke posttest dibuktikan dengan nilai $\mathrm{t}(25)=13,41, p=0,000$, besar peningkatan sebesar $27 \%$. Pada kelompok PBL-Jigsaw, hasil belajar meningkat secara signifikan dari pretest ke 
posttest dibuktikan dengan nilai $\mathrm{t}(25)=11,74, p=0,000$, besar peningkatan sebesar $28 \%$.

Temuan penelitian ini mendukung hasil penelitian yang lain bahwa pembelajaran berbasis masalah memberikan kesempatan belajar kepada siswa untuk mencari berbagai cara yang sesuai dengan kapasitas mereka dalam memecahkan masalah dalam memenuhi kebutuhan belajar untuk dicapai oleh siswa (Kim, Belland, \& Axelrod, 2019). Di sisi lain, cooperative learning terbukti dapat meningkatkan motivasi belajar siswa (Artha, Syam T, \& Priambodo, 2020) yang berasal dari lingkungan belajar kompetitif dari cooperative learning (Jati, Hidayah, \& Wahyudi, 2019). Suasana belajar yang kompetitif dianggap sebagai variabel penting dalam meningkatkan kesenangan siswa dalam belajar yang berimplikasi pada motivasi belajar (Andrian, Suroto, Tuasikal, Dhani, \& Setyorini, 2020). Sehingga tidak berlebihan apabila hasil penelitian ini dapat menganggap bahwa kombinasi antara pembelajaran berbasis masalah dengan cooperative learning dapat menjadi alternatif pilihan untuk meningkatkan motivasi belajar siswa yang selanjutnya berimplikasi dengan hasil belajar siswa.

Tabel 4. Perbedaan Peningkatan Motivasi dan Hasil Belajar antara PBL-TGT dan PBL-Jigsaw

\begin{tabular}{lcccccc}
\hline & \multicolumn{2}{c}{ Group } & \multicolumn{3}{c}{ Levene's Test } & \multicolumn{3}{c}{ Uji beda $\Delta$ Mean } \\
\cline { 3 - 7 } & & $F$ & Sig. & $t$ & $d f$ & Sig. \\
Motivasi & TGT x Jigsaw & 0,614 & 0,437 & $-0,963$ & 50 & 0,340 \\
belajar & & & & & & \\
Hasil belajar & TGT x Jigsaw & 0,197 & 0,659 & 0,000 & 50 & 1,000 \\
\hline
\end{tabular}

Pada tabel 3, hasil t-test independent menunjukkan bahwa tidak ada perbedaan peningkatan motivasi $[\mathrm{t}(50)=0,963, p=0,34]$ dan hasil belajar $[\mathrm{t}(50)=$ $0,000, p=1,000]$. Hal ini menunjukkan bahwa problem based learning dikombinasikan dengan tipe TGT dan Jigsaw sama baiknya dalam meningkatkan motivasi dan hasil belajar siswa. Sayangnya, bukti dari hasil kombinasi dua model ini hanya pada motivasi dan hasil belajar.

Sehingga jelas bahwa penelitian ini memiliki keterbatasan berupa kurangnya eksplorasi interaksi sosial dalam proses pembelajaran, padahal proses sosial ini merupakan variabel penting dalam penerapan model pembelajaran cooperative (Guzmán \& Payá, 2020). Selain itu, critical thinking yang juga menjadi inti dalam 
proses pembelajaran berbasis masalah tidak dibahas secara mendalam (Heaviside, Manley, \& Hudson, 2018). Kombinasi keduanya diyakini sangat ideal. Problem based learning dapat menguatkan cooperative learning yang memang pada dasarnya telah terbukti memberikan wahana belajar siswa untuk bekerjasama dalam menyelesaikan masalah secara kolaboratif sehingga pemikiran kritis dapat diasah (Wallhead \& Dyson, 2017). Dengan mempertimbangkan keterbatasan tersebut, sebetulnya memberikan peluang untuk penelitian selanjutnya agar lebih mendalam untuk membahas tentang dua variabel penting tersebut.

\section{SIMPULAN}

Model eklektik yang mengombinasikan problem based learning dan cooperative learning terbukti dapat meningkatkan motivasi dan hasil belajar baik pada tipe TGT ataupun Jigsaw. Dua tipe cooperative learning yang diterapkan tidak menunjukkan perbedaan yang signifikan dalam meningkatkan motivasi dan hasil belajar. Artinya, problem based learning cocok dikombinasikan dengan dua tipe model tersebut dalam meningkatkan motivasi dan hasil belajar. Keterbatasan penelitian ini adalah belum dibahas tentang interaksi sosial yang menjadi karakter utama penerapan model cooperative learning dan critical thinking yang menjadi core penerapan problem based learning. Untuk itu, rekomendasi selanjutnya adalah sebisa mungkin dapat diteliti juga interaksi sosial dan critical thinking dalam penerapan kedua model ini.

\section{DAFTAR RUJUKAN}

Andrian, R., Suroto, S., Tuasikal, A. R. S., Dhani, S. S. S., \& Setyorini, S. (2020). Efektivitas Model Pembelajaran Motorik Berbasis Movement Based Games Pada Siswa Sekolah Dasar. JOSSAE (Journal of Sport Science and Education), 5(1), 64-74.

Artha, A. A., Syam T, A. R., \& Priambodo, A. (2020). The Application of Teams Games Tournament (TGT) and Teaching Game for Understanding (TGfU) Learning Models on Learning Motivation and Volley Ball Passing Skills. Budapest International Research and Critics in Linguistics and Education (BirLE) Journal, 3(1), 46-53. https://doi.org/10.33258/birle.v3i1.751

Awe, E. Y., \& Benge, K. (2017). Hubungan Antara Minat Dan Motivasi Belajar Dengan Hasil Belajar Ipa Pada Siswa SD. Journal of Education Technology, 1(4), 231. https://doi.org/10.23887/jet.v1i4.12859 
Bores-García, D., Hortigüela-Alcalá, D., Fernandez-Rio, F. J., González-Calvo, G., \& Barba-Martín, R. (2020). Research on Cooperative Learning in Physical Education. Systematic Review of the Last Five Years. Research Quarterly for Exercise and Sport. https://doi.org/10.1080/02701367.2020.1719276

Burstiando, R. (2015). Peningkatkan Motivasi Intrinsik dan Ekstrinsik Melalui Sport Education Model pada Permainan Bolabasket. Jurnal Sportif, 1(1), $60-73$.

Fraenkel, J. R., Wallen, N. E., \& Hyun, H. H. (2012). How to Design and Evaluate Research In EducatIon (6th ed.). New York: Mc Graw HIll.

Gunawan, E. (2019). Motivasi Bermain Bola Basket Siswa Sma Negeri 12 Makassar. Jp.jok (Jurnal Pendidikan Jasmani, Olahraga Dan Kesehatan), 2(2), 14-23. https://doi.org/10.33503/jpjok.v2i2.447

Guzmán, J. F., \& Payá, E. (2020). Direct Instruction vs. Cooperative Learning in Physical Education: Effects on Student Learning, Behaviors, and Subjective Experience. Sustainability, 12(12), 4893. https://doi.org/10.3390/su12124893

Heaviside, H. J., Manley, A. J., \& Hudson, J. (2018). Bridging the gap between education and employment: A case study of problem-based learning implementation in postgraduate sport and exercise psychology. Higher Education Pedagogies, 3(1), 463-477. https://doi.org/10.1080/23752696.2018.1462095

Hung, W., Mehl, K., \& Holen, J. B. (2013). The Relationships Between Problem Design and Learning Process in Problem-Based Learning Environments: Two Cases. Asia-Pacific Education Researcher, 22(4), 635-645. https://doi.org/10.1007/s40299-013-0066-0

Jati, A. W. K., Hidayah, T., \& Wahyudi, A. (2019). The Implementation of Team Games Tournament Learning Model to The Volleyball Play Technique in Randudongkal Junior High School. Journal of Physical Education and Sports, 8(4), 32-37.

Kim, N. J., Belland, B. R., \& Axelrod, D. (2019). Scaffolding for optimal challenge in $\mathrm{k}-12$ problem-based learning. Interdisciplinary Journal of Problem-Based Learning, 13(1). https://doi.org/10.7771/1541-5015.1712

Metzler, M. W. (2011). Instructional Models for Physical Education (3rd ed.). New York: Routledge.

Meyers, L. S., Gamst, G. C., \& Guarino, A. J. (2013). Performing Data Analysis Using IBM SPSS. John Wiley \& Sons, Inc.

Ministry of National Education of Republic of Indonesia. (2016). Panduan Pembelajaran untuk Sekolah Menengah Pertama (1st ed.). Jakarta: Direktorat Jenderal Pendidikan Dasar dan Menengah. 
Nuriawati, I., Suroto, S., Tuasikal, A. R. S., \& Setyorini, S. (2020). Efektivitas Model Permainan Target Berbasis Goal Orientation Pada Pendidikan Jasmani. Multilateral Jurnal Pendidikan Jasmani Dan Olahraga, 19(1). https://doi.org/10.20527/multilateral.v19i1.8313

Prakoso, B. B. (2015). Upaya Peningkatan Kualitas Proses Belajar Mengajar PJOK melalui Evaluasi Diri Guru. In Optimalisasi Hasil-Hasil Penelitian dalam Menunjang Pembangunan Berkelanjutan (pp. 510-523). Makassar.

Suroto. (2017). Inovation Teaching Method for Physical Education Teacher in Indonesia. In Proceeding 2nd International Conference of Sport Science (pp. 94-107). Surabaya: Unesa University Press.

Suroto. (2018). Active Learning Model in Track and Field Course for Pre-service Physical Education Teacher. In Proceedings of the 2nd Social Sciences, Humanities and Education Conference: Establishing Identities through Language, Culture, and Education (SOSHEC 2018). Paris, France: Atlantis Press. https://doi.org/10.2991/soshec-18.2018.68

Todd, E. L., Begoña, C.-R., \& Carol, C. I. (2016). An evaluation of teachers' knowledge and use of physical education instructional models. Journal of Physical Education and Sport ( (JPES), 16(208), 1310-1315. https://doi.org/10.7752/jpes.2016.04208

Wallhead, T., \& Dyson, B. (2017). A didactic analysis of content development during Cooperative Learning in primary physical education. European Physical Education Review, 23(3), 311-326. https://doi.org/10.1177/1356336X16630221 